\title{
THE NOVEMBER MEETING IN URBANA
}

The six hundred fifty-second meeting of the American Mathematical Society was held on Saturday, November 25, 1967, at the University of Illinois in Urbana, Illinois. There were 254 registrants, including 216 members of the Society.

By invitation of the Committee to Select Hour Speakers for Western Sectional Meetings, there were two invited addresses. Professor Donald J. Lewis, of the University of Michigan, who was introduced by the Associate Secretary, spoke on Arithmetic and algebraic properties of value sets of polynomials. Professor Mark E. Mahowald, of Northwestern University, addressed the Society on the topic $A$ survey of homotopy theory of spheres. He was introduced by Professor MaryElizabeth Hamstrom.

By invitation of the same Committee there was a session of selected twenty-minute papers on Categorical Algebra, arranged by Professor Saunders Mac Lane. It included papers by Michael Barr, Fred E. J. Linton, John W. Gray, F. William Lawvere, and Jon M. Beck.

There were two sessions for contributed ten-minute papers. Professors I. David Berg and Joseph J. Rotman were the session chairmen.

On Friday, November 24, 1967, the day before the meeting of the Society, the University of Illinois sponsored a symposium on the Theory of Finite Groups with the financial support of the G. A. Miller Endowment. This symposium was in commemoration of the Centennial Year of the University of Illinois. The speakers and their titles were as follows: Professor Reinhold Baer, University of Frankfurt and New Mexico State University, Conditional identities and principal factors of finite groups; Professor Richard Brauer, Harvard University, Lower defect groups of blocks in the theory of representations of finite groups; Professor Graham Higman, Oxford University, The simple group of Donald Higman and Charles Sims; Professor Robert Steinberg, UCLA and Yale University, Algebraic groups and finite groups; Professor John Thompson, University of Chicago, p-signalizers and groups of orders prime to 3; and Professor Helmut Wielandt, University of Tübingen, Permutation representations.

There was a reception for those attending the meeting on Friday from $4: 30$ to 6:00 P.M. in the Illini Union.

URBANA, ILLINOIS Associate Secretary 